\title{
FIRE ACCIDENT PREVENTION SYSTEM IN HEAVY VEHICLES
}

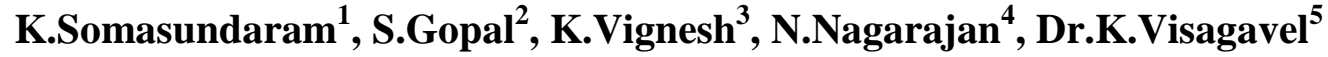 \\ ${ }^{1}$ Student, Mechanical Engineering, Knowledge Institute of Technology, Tamilnadu, India \\ ${ }^{2}$ Student, Mechanical Engineering, Knowledge Institute of Technology, Tamilnadu, India \\ ${ }^{3}$ Student, Mechanical Engineering, Knowledge Institute of Technology, Tamilnadu, India \\ ${ }^{4}$ Asst.Professor, Mechanical Engineering, Knowledge Institute of Technology, Tamilnadu, India \\ ${ }^{5}$ Professor\&Head, Mechanical Engineering, Knowledge Institute of Technology, Tamilnadu, India
}

\begin{abstract}
Generally Fire Accidents in Heavy Vehicles occur due to many reasons like Short Circuit of Electrical Connections, Bringing Flammable Materials and Indiscipline activities of People. So Passengers die in a large number including Children. It is mainly focused to safeguard the Passengers in Buses and Trains. During Fire Accidents, They have only two ways to escape, one is the Main Way and another is the Emergency Exit, so they cannot escape quickly and easily. By changing the Design of the body of the Vehicle, They can escape easily. By using the slider mechanism
\end{abstract}

Keywords: Fire, Body of the Vehicle, Emergency Exit, Microcontroller, stepper motor.

\section{INTRODUCTION}

Generally, while considering Buses, during accidents they have only two ways to escape, one is through the main way and another is through the emergency exit. Though there were this many ways to escape, occurrence of Fire Accidents were still more in number. In this system, by changing the design of the Vehicle Body, Passengers can escape easily. Normally in buses, the sides have windows and they remain closed. We are changing the design of the both sides in the body of the vehicle.

\section{OVERVIEW OF THE PROJECT}

The main objective of our project is to protect passenger from fire accidents. Fire Accidents in heavy vehicles is a major issue. It occurs due to many reasons like Short Circuit of Electrical Connections, Bringing Flammable Materials and Indiscipline activities of People. Due to this, there is more human loss. During Fire Accidents, Passengers have only two ways to escape in vehicle, one is the Main way and another is the Emergency Exit. They cannot move easily and quickly.

In this system, the external sides of the body are designed as a slider which slides when the signal is received from sensor. During occurrence of fire, the temperature sensors sense the temperature and send signal to the Motor, which results in movement of slider and also manual operating system with glass guard provided with driver. So people can escape easily and quickly.

\section{WORKING OF THE SYSTEM}

\subsection{General Working}

Initially, during occurrence of fire, there is a temperature sensor which senses the temperature of the body and gives a signal. By this signal the slider movement takes place. The
Slider movement is controlled by a motor. As the signal reaches, the motor starts to operate and the Slider moves. The Power is transmitted from the Motor to slider by Chain. Now as the slider moves to an end, there will be a free space where it will be easy for the passengers to escape.

\section{STATIC CONDITION}

Initially, during occurrence of fire, there is a temperature sensor named LM35, which senses the temperature of the body and gives a signal. By this signal the slider movement takes place. The Slider movement is controlled by a Stepper DC motor. The drive and control of Motor is done by Microcontroller AT89652. As the signal reaches, the motor starts to operate and the Slider moves. The Power is transmitted from the Motor to slider by Chain. Now as the slider moves to an end, there will be a free space where it will be easy for the passengers to escape.

\subsection{Schematic Diagram of Static Condition}

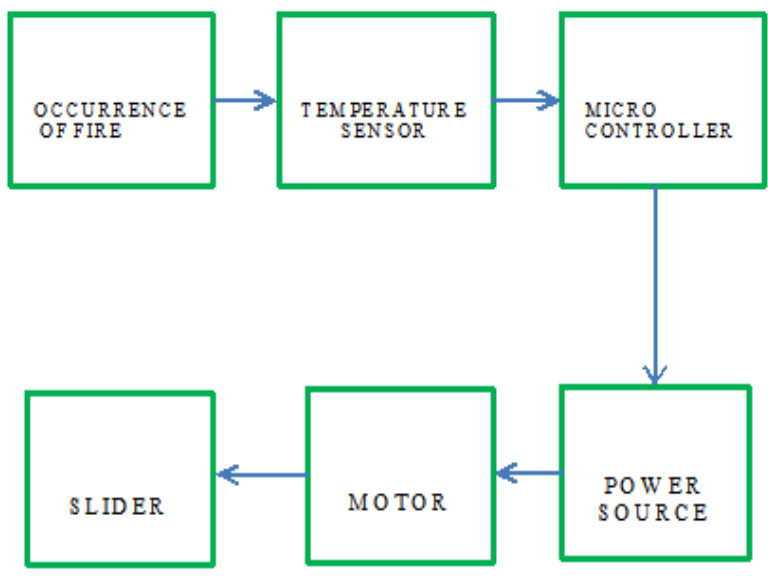




\section{DYNAMIC CONDITION}

In some cases, the vehicle may be in motion and Passenger may unable to get out of the vehicle during Fire. For certain conditions, the temperature sensor senses the temperature of the body and then it makes a signal. By this signal the fuel gets cut off by the Throttle Sensor and there will be no fuel going to the engine. Due to this the vehicle will remain in rest condition. Then the Microcontroller again controls and drives the motor. It will operate and make the slider to move, the movement is by Chain. By this passengers can escape easily and quickly.

\subsection{Schematic Diagram of Dynamic Condition}

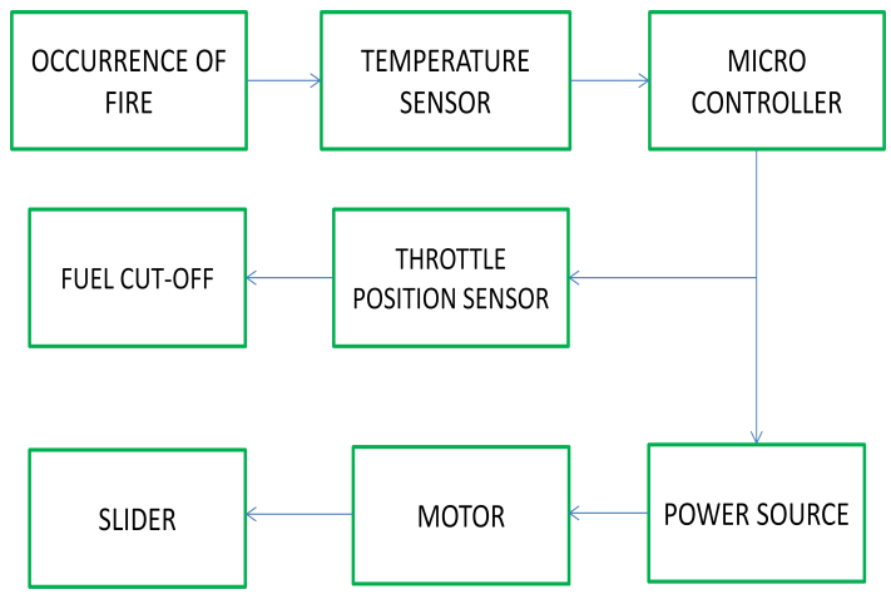

\section{CONCLUSIONS}

Hence, by implementing this system large amount of Human Life can be saved. It can be implemented in AC coach buses, where more fire Accidents occur. Then we have better advantage to save the people.

\section{ACKNOWLEDGEMENTS}

This work was supported by Department of mechanical Engineering in Knowledge institute of technology. We are extremely grateful to thank our principal Dr.PSS.Srinivasan for providing all facilities to complete this project. The authors appreciate the support of Dr.K.Visagavel, Professor $\&$ Head- Department of Mechanical Engineering and Mr.N.Nagarajan, Asst. Professor, Mech.

\section{REFERENCES}

[1]. Rompe and Krüger, (1985). "Research on Emergency Exit System for bus safety" Technical report

[2]. Shiosaka and Kuboike, (1996). "Research on emergency exit system for school bus safety Technical report 